\title{
Problemas e limites da utilização do conceito de classe social em investigações epidemiológicas: uma revisão crítica da literatura 1
}

\author{
Problems and limits in the utilization of the \\ concept of social class in epidemiologic research: \\ a critical review of the literature 1
}

Jorge José Santos Pereira Solla 2

${ }^{1}$ Artigo baseado em dissertação de Mestrado apresentada ao Programa de Saúde Comunitária da Universidade Federal da Bahia.

2 Instituto de Saúde Col etiva, Universidade Federal da Bahia. Rua Padre Feijó 29, 4 o andar, Salvador, BA, 40110-170, Brasil.
Abstract The application of inductive empirical variables in hegemonic alternatives of Epidemiology in order to treat soci oeconomic variations in human groups has displayed certain limitations raising the need for new proposals. The use of social class was thus introduced as an analytical category operated according to place in the productive process for the subjects under study. This choi ce has al ready shown potential ities in several studies. This paper was intended to identify some limits and problems occurring when using the social class concept in epidemiological research. Besides the need for an adequate theoretical framework, construction of categories consistent with both their theories and the levels of abstraction employed, and the concern for more carefully analyzing the consumer and working modes for each social class (questions that have been discused el sewhere), this paper approaches several issues, as follows: the treatment of social classes as articulated clusters in the research process, the need to adjust the operational scheme to the particularities of each socioeconomic formation, the simplification resulting from the process of reducing the concept of social class to several linked variables, the need for a relativel y large sample, the existence of debate over the definition of the position of class groups not participating in production, and subjects with two or more different positions in production.

Key words Social Class; Epidemiology; Social Stratification

Resumo Aslimitações evidenciadas no emprego de variávei s empírico-indutivas nas alternativas hegemôni cas da Epi demiologi a para o tratamento das variações sócio-econômicas em coleti vos humanos levaram à necessi dade de novas propostas. Assi m, foi introduzido o emprego da categoria classe social, operacionalizada de acordo com a inserção produtiva dos indi víduos estudados, apresentando potencialidades já evi denciadas em alguns estudos. O presente trabalho buscou identificar problemas elimites existentes na utilização do concei to de classe social na investigação epidemiológica. São abordados neste artigo al guns aspectos, entre el es: o tratamento das classes sociais enquanto agregados arti culados no processo de investi gação, a necessi dade de adequar o esquema de operacionalização às particularidades de cada formação sócio-econômica, a simplificação efetivada no processo de redução do concei to de classe a uma série de variávei s articuladas empregadas, a necessi dade de amostra relativamente grande, a existência de controvérsi as na definição da inserção de classe de segmentos afastados da produção e de indivíduos com duas ou mais inserções produtivas distintas.

Palavras-chave Classe Social; Epidemiologia; Estratificação Social 


\section{Introdução}

As alternativas hegemônicas e clássicas da Epidemiologia para o tratamento das variações sócio-econômicas nos coletivos humanos estudados sofrem as limitações referentes ao processo de redução/simplificação impostas pela construção de variáveis a partir dos conceitos estabelecidos. A desarticulação com o real e o distanciamento conceito-variável estão presentes, apesar de, em geral, tal problema ser escamoteado. As limitações evidenciadas no emprego deste tipo de variáveis (empírico-indutivas) fez com que surgissem novas propostas que demandaram outro marco teórico. "O novo marco interpretativo determinava a necessidade de discriminar (...) a qualidade de vida e as condições epidemiológicas das classes sociais e, por isso, boa parte do esforço realizado nessas etapas, seja frente ao processamento de dados secundários ou para o desenho de inquéritos, foi para definir eoperacionalizar novos sistemas de estratificação social, posto que as estratificações empiristas que se haviam empregado até esse momento, partiam de critérios empírico-indutivos de estratificação por variáveis" (CEAS, 1990).

Assim, foi introduzido o emprego da categoria classesocial com base no conceito elaborado por Lenin (1980), e operacionalizado a partir da inserção produtiva das relações sociais, relações técnicas e relações de distribuição (Barros, 1986; Bronfman \& Tuirán, 1984; Bronfman et al., 1988). Estes trabalhos empreenderam uma linha de investigação a respeito da dial ética da reprodução social. “Essa nova estratificação assinalava a necessidade de identificar as classes segundo seu vínculo estrutural e não pelos efeitos da mesma (tais como: a renda, o nível educativo e outras características componentes e derivadas da inserção). Era a etapa em que se buscava discriminar transversalmente as classes para comparar seus índices epidemiológicos" (CEAS, 1990).

Tais estudos têm avançado tentando ampliar os níveis de explicação dos diferenciais observados desenvolvendo a linha de investigação que foi denominada por alguns autores de Epidemi ol ogia do Consumo. “É interessante ressaltar o avanço metodológico que experimentou em anos posteriores a investigação dos determinantes da saúde-enfermidade na esfera do consumo, porque assumiu o conhecimento da gênese ou movimento da determinação epidemiológica e não só o contraste transversal dos diferenciais" (CEAS, 1990).

No entanto, Barreto (1990) refere um declínio nos últimos anos na produção científica em Epidemiologia fundada na Sociologia Marxista, atribuindo como uma das razões para tal queda a existência de problemas conceituaise metodológi cos para os quais ainda não foram desenvolvidas soluções adequadas, o que determina dificuldades para o teste dos model os teóricos empregados em situações empíricas concretas.

A consolidação do uso do conceito de classe social em epidemiologia, o aprimoramento dos modelos de análise, assim como o emprego de variáveis que resgatem as particularidades de uma determinada formação sócio-econômica fazem parte das tarefas necessárias para o estabelecimento de um aparelho conceitual e de um arsenal metodológico que estabeleçam as conexões entre as categorias dos processos globais da sociedade e o processo saúde-doença.

Ao empregarmos o conceito de classe social na investigação epidemiológica, não basta reconhecermos suas potencialidades. Torna-se imprescindível identificarmos problemase elimites existentes na sua utilização e enfrentarmos adequadamente al gumas questões essenciais para alcançarmos uma maior capacidade explicativa das determinações investigadas.

Além da necessidade de adequação do marco teórico utilizado, da construção de categorias coerentes com a teoria e com os níveis de abstração empregados, e do aprofundamento da análise das formas de trabalho e consumo em cada classe social (questões anteriormente discutidas) (Solla, 1990), merecem destaque os aspectos que abordaremos a seguir.

I. Na análise empírica, as classes sociais são tratadas isoladamente, não refletindo completamente as relações de oposição (dominação-subordinação) existentes na estrutura de classes, sendo trabalhadas enquanto agregados articulados no processo da investigação, construídos a partir da inserção na produção de cada indivíduo/família participante.

A própria construção do modelo teórico empregado realiza um recorte da realidade, simplifica-a e delimita uma determinada questão. Segundo Almeida Filho (1989), ao criar e desenvolver modelos, o cientista faz uma opção de paralisar a realidade. "Toda vez que se institui um símbolo ou um conjunto de símbolos (outra definição de modelos) os objetos reais que se constituem em sua referência se quedam, a esse nível, paralisados apesar de as coisas (as causas) que se busca representar não pararem de se mover. É realmente necessário fazer cortes de congelamento; na prática, um modelo é exatamente essa paralisação. Em ou- 
tras palavras, de modo mais superficial, podemos dizer que um modelo é como um desenho dos nexos que o cientista pretende enxergar na natureza ou na sociedade, e não o resultado sistematizado do que a natureza ou a sociedade estão dizendo a partir de observações ou experimentos".

Esta é exatamente a utilidade de empregar modelos no processo investigativo: para simplificar a realidade e delimitar uma questão específica. "A provisoriedade dos modelos, criados para serem destruídos pelo processo de pesquisa, recupera parcialmente a dinâmica dos processos reais perdida, quando da sua paralisação em um sistema de hipóteses (...)" (Almeida Filho, 1989).

Em relação ao problema enfocado, ou seja, a utilização do conceito de classe social na investigação epidemiológica, demandando sua operacionalização através de um conjunto de variáveis articuladas, estabelece-se uma limitação intrínseca a este processo de investigação. Ressaltamos que estes estudos têm a pretensão de investigar fenômenos dinâmicos processo saúde-doença - como se fossem situações definidas pontualmente, e que, com uma abordagem transversal ou mesmo longitudinal (com tempo relativamente pequeno de acompanhamento), pudessem ser compreendidas plenamente e ter desvendadas suas determinações. Bronfman \& Tuirán (1984) consideram que "os inquéritos não permitem apreender as classes como totalidades, isto é, em suas mutações internas e em suas relações com as demais classes e com a estrutura social em seu conjunto".

Nosso recorte da realidade busca estabelecer critérios, a partir dos quais possamos identificar grupos de indivíduos agregados pelo fato de apresentarem concordância com tais critérios. A inserção de cada indivíduo na produção definirá o agregado no qual irá ser "alocado". Cada agregado corresponderá a uma classe social ou fração de classe específica. O modelo pressupõe que esta correspondência permita que cada agregado reúna as condições de existência (de vida, de saúde) próprias daquela classe social. Pretende-se que cada agregado represente a sua classe social correspondente. As relações de oposição (dominação-subordinação) existentes na estrutura de classes só serão reveladas na medida em que estejam representadas nos critérios utilizados na construção das variáveis que irão definir a classe social na investigação empírica.

Contudo, a dinâmica da formação econômico-social enfocada extrapola os limites impostos pelo nosso recorte e pelo conjunto de variáveis empregadas. “Ao analisar uma questão da formação social usando uma idéia de causa e efeito, adotando o caminho de desenvolver modelos, estaremos automaticamente fazendo uma opção: parar a realidade. Toda vez que se tenta armar um conjunto de símbolos em uma estrutura, o real é logo imobilizado, porque as coisas que estão sendo representadas continuam a mover-se e a existir. Isso é um dilema, porque de fato não se pode diretamente apreender a dinâmica da coisa paralisando-a. Porém o que produzirá o conhecimento sobre ela é a elaboração que se pode fazer depois" (Almeida Filho, 1989).

Tais limites não devem implicar afastamento do enfrentamento com o real; estes problemas não devem se transformar em impedimentos para a investigação empírica. Por outro lado, tal afirmação não implica advogar o empiricismo. Para Almeida Filho (1992), o empiricismo corresponde ao: “(...) referencial filosófico que advoga uma ciência neutra, livre de vaIores, que apreenderia a realidade sem mediações, sendo os conceitos científicos imediatamente redutíveis à observação. Para o empiricismo puro o conceito será, fundamentalmente, definição operacional. Por isso o empiricista é muitas vezes chamado de reducionista (...)". Breilh (1989), trazendo a discussão sobre o papel do plano empírico nas investigações que incorporam as contribuições do marxismo para a produção de conhecimento, ressalta que, apesar de o marxismo partir do conhecimento empírico para construir seu objeto de estudo, o submetea um processo de elaboração teórica através do qual será estabelecido um concreto científico, incorporando as características essenciais existentes.

Contudo, alguns autores, como Wright (1981) e Almeida Filho (1989), consideram que no processo de crítica e combate ao "estrutural-funcionalismo" observou-se uma tendência de estudos que incorporaram o materialismo histórico a desprezar o empírico. Para Almeida Filho (1989), “(...) não se pode parar na intenção da teoria. É necessário a prática para sair do começo (de tudo). Se não tivermos uma prática que seja uma constante crítica do seu próprio referencial, o trabalho que se quer científico não pode ter um estatuto de discurso teórico. Deixa mesmo de ser científico. Deixa mesmo de ser político". 
1I. As classes so ciais não são categorias nominais que possam ser definidas a partir de um esquema aplicável a qualquer sociedade, sem considerar as peculiaridades de cada formação econômico-social estudada.

Uma formação sócio-econômica concreta, objeto de determinada investigação, apresenta ao seu interior uma articulação específica de modos de produção, sendo composta por um modo de produção hegemônico, fundamental, e, eventualmente, por outros secundários a ele subordinados. Daí já deriva a existência de classes sociais e frações de classe que, enquanto resquícios de outros modos de produção e mesmo quando em processo de eliminação real, são evidenciadas na investigação social (Poulantzas, 1977). Como exemplo, temos a Pequena Burguesia, classe remanescente de modo de produção anterior, com existência subordinada no interior do modo de produção capitalista.

Além disso, um dado modo de produção apresenta uma lógica própria de evolução, desenvolvendo-se através de diferentes estágios. Cada estágio pode apresentar formas distintas de relações sociais refletindo-se em superestruturas político-ideológicas diferenciadas. Assim, torna-se necessário realizar adequações na operacionalização do conceito de classe social que sejam coerentes com as características da formação econômico-social investigada e de sua estrutura social.

Para Jiménez (1982), ao estudarmos um determinado fenômeno social, se não levarmos em consi deração a estrutura econômica da formação social concreta, apenas conseguiremos “(...) resultados unilaterais, representações mecanicistas, que em lugar de aclarar os processos os deforma (...)". Também Victora et al. (1990) trazem esta questão: “Outro aspecto complexo é a necessidade de que a operacionalização seja precedida de um estudo detaIhado da formação sócio-econômica local, e das características da produção, que permita avaliar a inserção de classe de diferentes categorias profissionais. Por exemplo, um operário da construção civil que, em uma região com alta rotatividade de mão-de-obra e baixo nível de emprego, pode ser enquadrado no subproletariado, pode igualmente ser inserido no proletariado típico em uma região onde haja escassez deste tipo de mão-de-obra e, portanto, pleno emprego. Isto significa que, qualquer esquema de operacionalização não pode ser generalizado, havendo necessidade de adaptações locais".
III. Dificuldade de operacionalização do conceito de classe social, sendo feita uma simplificação neste processo de redução do conceito a uma série de variáveis articuladas, que a partir do concreto empírico, irão definir a classe social a que pertence determinado indivíduo/família.

Em seus processos investigativos, a Epidemiologia faz uso da quantificação dos eventos e determinantes estudados, sendo típico de seu raci ocínio a redução do real através de model os teóricos, os quais são avaliados com base em raci ocínios indutivos de base estatística (Almeida Filho, 1989).

Assim, a partir do modelo teórico, a investigação desce para o nível empírico. Como os conceitos estão distantes do real, “(...) o conjunto abstrato que armamos a partir desses termos, o modelo, só terá suas relações internas devidamente espel hando a realidade quando os seus conceitos forem reduzidos ao real pelo processo de pesquisa. O campo da investigação teórica e o da investigação empírica fazem parte de um mesmo conjunto. O quadro teórico envolve também os conceitos que sairão para a realidade. Acontece que, como os conceitos que estão no nível da abstração não podem se sujar, a linha do quadro teórico é deslocada artificialmente, transformando os conceitos em variáveis. (...) O que podemos fazer é propor sucedâneos (...) que tenham uma correspondência objetiva (variáveis ou equivalentes). (...) Dessa forma o que para nós eram conceitos largos e abstratos (...), tornam-se dados da realidade concreta, com a qual poderemos enfim lidar. É interessante notar que, nessa abordagem, o processo de análise inverte o processo de redução" (Almeida Filho, 1989).

Almeida Filho (1989) traz um exemplo deste processo de redução dos conceitos para sua utilização na investigação empírica, percorrendo através de reduções sucessivas o caminho entre o conceito e a medida a ser empregada. Determinada pesquisa assume em seu quadro teórico o conceito de ocupação social do espaço, enquanto conceito central para a análise a ser desenvolvida. A partir deste conceito, é construída uma variável: densi dade populacional, a qual será expressa através de dois indicadores: densidade interna e densidade externa. Densidade interna será medida pelo número de habitantes por cômodo e pelo número de metros quadrados por habitantes. Densidade externa utilizará como medida o número de habitantes por superfície. O conceito foi assim reduzido a uma variável com dois indicadores.

Contudo, este autor chama atenção para problemas existentes neste percurso. Para ele, 
o processo de redução nem sempre pode ser percorrido por todas as variáveis. Considera que a representação do conceito de classe social através de um "conjunto de indicadoresmedidas" pode ser problemática. As críticas podem ter como alvo a infidelidade metodológica ao marco teórico, ou dizer respeito às dificuldades no processo de redução concei to-variável-indicadores-medidas (Almeida Filho, 1989). Este processo de simplificação/ redução não implica assumir uma ótica típica do reducionismo, o qual, segundo Breilh (1989), “(...) interpreta as propriedades dos conjuntos mais complexos em termos das suas unidades componentes, infere as propriedades do todo a partir das propriedades intrínsecas das partes, as quais existiriam a parte de e ante das propriedades do todo".

O aporte do marxismo à investigação em nossa área tem dado contribuições fundamentais para o enfrentamento de tal questão, superando a ótica reducionista. "A aproximação marxista da epidemiologia rebaixa o plano dos fenômenos empíricos e amplia o princípio de causalidade porque assume uma aproximação dialética. A construção do objeto de estudo que deve transformar-se, não abstrae as propriedades das partes, como a saúde-enfermidade, do todo em que estas existem, e sim as observa como produto de sua vinculação com o todo. (...) se bem o todo social se componhe de partes que podemos descrever e medir empiricamente, a participação dessas partes no todo gera uma realidade complexa, superior, que resulta com qualidades diferentes, das partes, ainda que dependa destas para sua existência" (Breilh, 1989).

O que ocorre quando efetivada esta redução é uma passagem necessária para a construção de variáveis que traduzam para o plano da investigação os conceitos teóricos, buscando assegurar a coerência com a teoria apesar do recorte efetivado. Tal processo implica perda substancial, contudo é indispensável para a operacionalização de conceitos teóricos em variáveis na análise empírica.

Para Victora et al. (1990), “a simplificação, no entanto, é um processo inerente à pesquisa quantitativa em Epidemiologia: por exemplo, para classificar uma criança como desnutrida utiliza-se uma ou duas medidas - peso e/ ou altura - entre dezenas de medidas possíveis, compara-se esta medida com um padrão de referência mais ou menos arbitrário e decide-se sobre um ponto de corte também arbitrário. Nesse processo simplificatório, é inevitável que se perca informação e que ocorram erros de classificação, mas a própria coerência dos re- sultados empíricos pode servir para avaliar até que ponto a simplificação pode ter sido excessiva".

Portanto, a coerência dos resultados empíricos e a fi del i dade ao marco teórico do concei to podem exprimir a capacidade que possuem as variáveis coletadas no plano empírico da investigação de possibilitar o resgate do potencial explicativo do conceito empregado para a análise em questão.

IV. A necessidade de estabelecer determinados pontos de corte arbitrários, como ocorre com a utilização na operacionalização de variáveis quantitativas, como renda, número de empregados e tamanho da propriedade rural.

A maior parte das variáveis que são articuladas para operacionalizar o conceito de classe social nas propostas estudadas são variáveis qualitativas, com definições relativamente estabelecidas, sem muitas ambigüidades. No entanto, quando surgem variáveis quantitativas, como no caso do emprego de renda e de número de empregados, novos problemas são acrescentados. A delimitação de "pontos de corte" pode alterar a "sensibilidade" e a "especificidade" de uma classificação. Definir pontos de corte pode propiciar "bias" na investigação.

No caso da renda, a definição de um ponto de corte sofre grande dose de arbitrariedade. Enquanto Barros (1986) usou como critério para separar a Burguesia da Nova Pequena Burguesia o fato de apresentar uma renda maior ou igual a nove salários mínimos para a primeira classe e de possuir uma renda menor que nove salários mínimos para a segunda, Bronfman et al. (1988) utilizaram 15 salários mínimos como ponto de corte. As particularidades da sociedade estudada, as variações nos padrões de renda, os efeitos de conjunturas recessivas vão determinar grandes distinções neste limite que dividiria estas duas classes a partir desta variação quantitativa.

Também para o emprego da variável “número de empregados" tal questão se repete. Para Wright (1981) não existe a priori um critério para definir que número de empregados transformaria o pequeno burguês em pequeno empregador, variando de acordo com alterações na produção e épocas históricas diferenciadas.

Este problema não consegue ser superado através de critérios baseados em análises estatísticas da distribuição populacional destas variáveis, nem por uma delimitação precisa a partir somente da construção do modelo teórico empregado. Portanto, demanda novas alternativas que superem estes limites atuais. 
V. A qualidade das informações pode ser comprometida pelo número de variáveis necessárias e pela dificuldade de acesso a certos dados.

A utilização de um questionário excessivamente longo pode pôr em perigo a captação da informação em seu conjunto. Por outro lado, para operacionalizar o conceito de classe social, necessitamos levantar várias informações fundamentais para a construção das variáveis empregadas. Além disso, existem problemas relativos ao entendimento das pessoas a serem entrevistadas a respeito das questões formuladas. Diante disso, deve-se“(...) tentar alcançar um equilíbrio entre a concisão e a abrangência, o qual é muitas vezes difícil de ser atingido" (Barros \& Victora, 1991).

Breilh \& Granda (1986) consideram que “(...) a qualidade do formulário repousa fundamentalmente na adequada operacionalização das variáveis, que por sua vez depende do rigor científico com que se formulou a hipótese". Estes autores chamam atenção para o problema da tendenciosidade pelo uso de questionários, trazendo a advertência feita por Bradford Hill: “(...) as investigações mediante questionários são aquelas em que por excelência deve se suspeitar da possibilidade de tendenciosidade".

Um questionário pode "medir" um resultado que não é exatamente o que ele se propunha a "medir". Assim, podemos ter erros de "classificação" em termos da doença e/ ou da exposição. O erro de classificação é a principal conseqüência do "bias" de informação. Os "bias" de informação são distorções na estimativa do efeito de interesse no estudo resultante do erro na definição da condição de exposição ou da condição de doença. Indivíduo(s) que deve$\mathrm{ria}(\mathrm{m})$ fazer parte de um determinado agregado correspondente à classe social " $X$ " é (são) colocado(s) em outro(s) agregado(s) por problemas resultantes da qualidade das informações coletadas, ou, na segunda situação, o "efeito" sobre a saúde-doença não é adequadamente levantado, incorrendo também em um erro para o resultado da investigação (Kleinbaum et al., 1982).

VI. Necessidade de amostra relativamente grande, devido ao número de classes e frações de classe existentes e à pequena proporção de certas classes na população.

Um dos requerimentos explicitados para o desenvolvimento da análise epidemiológica dos dados registrados é que exista um número suficiente em todos os estratos de cada variável empregada (Kleinbaum et al., 1982).
No nosso problema - a operacionalização do conceito de classe social - -, duas questões estão colocadas: a primeira refere-se ao fato de existirem várias classes sociais e frações de classe, implicando a utilização de vários estratos em nossa "variável de exposição". Além disso, a distribuição das classes sociais na população apresenta pequena proporção em determinadas classes e maiores em outras, ou seja, a distribuição proporcional da população nas diversas classes sociais e frações de classe apresenta enorme variação.

Apenas desenhos de estudos que demandassem a construção de amostras, de forma que os estratos ("classes") tivessem o mesmo tamanho, iriam alterar tal quadro na investigação. Contudo, dessa forma, a amostra não seria representativa da população de estudo no que diz respeito à distribuição da categoria "chave" da investigação. Seria aplicada para avaliar as condições de vida e saúde de cada classe em particular e para comparar a de uma classe com a(s) de outra(s), no entanto não poderia fornecer parâmetros totalizadores.

Assim, o emprego do conceito de classe social em Epidemiologia, em estudos que pretendam garantir a representação da "pirâmide" das classes sociais e frações de classe existentes na formação sócio-econômica específica estudada, demanda a construção de grandes amostras apresentando em cada estrato número suficiente de forma a possibilitar o desenvolvimento da análise.

Admitindo a importância de investigar o papel de elementos mediadores entre a classe social e o processo saúde-doença, tal questão se torna ainda mais crítica, pois, ao interior de cada classe, a amostra deverá possuir um número de indivíduos suficientemente grande, de forma a permitir a estratificação pela suposta mediadora e a avaliação dos diferenciais observados, inclusive possibilitando o emprego de testes estatísticos das associações evidenciadas e das estimativas de efeito.

Cabe ressaltar que a distribuição proporcional das classes sociais e suas frações vai apresentar diferenças entre formações sócioeconômicas diversas de acordo com o estágio de desenvolvimento das forças produtivas e das relações de produção, com a lógica intrínseca da evolução da sociedade capitalista e com o papel predominante da produção naquela formação específica. 
VII. A classe social é um determinante distal, cuja ação é mediada por variáveis que possuem certo grau de autonomia relativa, podendo enfraquecer relações estatísticas entre a classe e o processo saúde-doença.

Victora et al. (1990) trazem esta questão apontando-a como sendo uma desvantagem, na medida em que “(...) sendo um determinante distal, cuja ação é mediada por uma série de variáveis que possuem certa autonomia, as relações estatísticas entre inserção de classe e o processo saúde-doença podem ser algo enfraquecidas".

É necessário compreender que, ao assumir uma visão dialética a respeito dos processos sociais (inclusive sobre o processo saúdedoença), a teoria marxista traz um novo enfoque acerca das relações entre a determinação e a liberdade. Como Breilh (1989) bem expressa: "O fato de que os processos da realidade sejam determinados ou sujeitos a leis, não significa que não seja factível a liberdade, pelo contrário “... se deve entender que a liberdade de ação é uma conseqüência da causação e não é incompatível com a mesma" (...) o surgimento e distribuição de condições epidemiológicas e enfermidade se dão em meio de uma trama de processos determinantes individuais e específicos. Um processo pontual que participa na produção da saúde-doença não é independente a respeito do conjunto de processos delimitados por uma lei epidemiológica mais ampla, mas é aleatório ou livre a respeito de cada uma das determinações mais pontuais. É importante compreender, neste sentido, que nossas condições biológicas especiais que as diferenciam das que caracterizam outros organismos nos têm permitido um desenvolvimento histórico consciente, com o qual temos transformado os limites da natureza e ampliado a liberdade". Também Przeworsky (1989) contribui para esta discussão, quando lembra que a inserção de classe abre uma estrutura de opções em termos comportamentais.

Portanto, existindo uma série de variáveis que assumem o papel de mediadores entre a classe social e o processo saúde-doença, sendo que a determinação social a partir da inserção produtiva do indivíduo constitui um campo de probabilidades, e existindo uma autonomia relativa de certos processos que se relacionam nesta rede de determinação, a determinação probabilística quantificada e expressa pela estatística não dá conta de identificar esta totalidade, em sua dinâmica, seu movimento e sua hierarquia.
VIII. A definição da inserção de classe de segmentos afastados da produção no momento da investigação, como aposentados, desempregados, donas de casa, estudantes e doentes/afastados, é muito controversa com várias alternativas.

Neste item, aspectos diversos estão englobados, acarretando problemas com repercussões e determinantes distintos. Algumas alternativas, como a empregada no "Projeto MorbiMortalidade Materno-Infantil em Salvador (BA), 1987/88 (UFBa/FAMED/DMP, 1986) de englobar todos estes casos em um grupo que tem como característica homogenizadora o fato de os "chefes" de família estarem afastados de uma inserção produtiva, estando fora da população economicamente ativa, demonstraram necessitar de reparos.

Em primeiro lugar, o fato de não ser identificada para os aposentados a sua inserção produtiva anterior faz com que fiquem em uma mesma categoria indivíduos que, se ainda estivessem "ativos", estariam em classes sociais distintas. Tratar, portanto, os aposentados como uma só categoria seria tentar ignorar grandes diferenças. Talvez, tomar a última inserção na produção antes de se aposentar como sendo o referencial para a inserção de classe destes indivíduos seja a melhor opção, conforme empregado por Wright (1981, 1985) (inserção passada - trajetória de classe). Todavia, ainda assim teríamos de lembrar que, ao aposentarem-se, os trabalhadores, em nossa formação sócio-econômica, geralmente sofrem uma perda real de poder aquisitivo que terá repercussões em suas condições de saúde e acesso a serviços de saúde. Em al guns casos, o aposentado pode vir a assumir outro trabalho durante o período de aposentadoria - o que pode até aumentar sua renda -, entretanto certas características da classe social (definida por sua inserção produtiva anterior) podem permanecer.

Com os desempregados, também são tratadas situações distintas. Existem indivíduos que, durante o período de investigação, podem estar temporariamente afastados de qual quer inserção produtiva; outros, apesar de serem considerados desempregados, desenvolvem esporadicamente "bicos", sendo contratados para tarefas específicas; finalmente, encontramse ainda indivíduos que são "cronicamente" desempregados, não conseguindo nenhuma inserção no mercado de trabalho, estando completamente à margem da população economicamente ativa. Estas situações também deveriam ter um tratamento diferenciado.

No tocante às donas de casa, poderíamos observar também certas particularidades. Al- 
gumas destas, além do trabalho doméstico, desenvolvem certas tarefas (venda de serviços) e/ ou realizam atividades produtivas (produção caseira) para venda, como forma de contribuir para a renda familiar. Outras estão como donas de casa provisoriamente, por terem sido demitidas de alguma inserção produtiva anterior e ainda não terem conseguido outra. Uma amostra composta por mulheres que tenham tido fiIhos recentemente encontra-se nesta última situação, pois o período do parto representa em muitos casos a perspectiva real de demissão do trabalho. Já outras, que vivem geralmente em famílias extensas, sendo viúvas ou separadas de seus ex-companheiros, recebendo ou não uma "pensão", dividem o custo das despesas familiares com outro(s) indivíduo(s) (irmãos, outros parentes, etc.). Portanto, existem condições diferenciadas também ao interior deste grupo.

Outras opções, como tomar a inserção de outro membro do núcleo familiar como a referência para a definição da classe social (Bronfman \& Tuirán, 1984), ou assumir estes grupos enquanto componentes do Subproletariado (Barros, 1986), não conseguem responder aos problemas aqui identificados.

Lembramos que a estrutura da família cujo "chefe" é aposentado ou dona de casa pode ser peculiar, apresentando diferenças em relação as outras famílias com "chefes" inseridos na produção. Quais seriam os efeitos destas peculiaridades sobre a saúde/ doença de seus membros? A proporção destas famílias na população pode também evidenciar determinadas características desta formação social que podem determinar situações diversas para o processo saúde-doença e sobre o acesso aos serviços de saúde. Registramos ainda que tais grupos, pela definição conceitual de classe social assumida (Lenin, 1980), não constituem classes sociais nem frações de classe.

IX. Os objetivos da investigação devem ser levados em conta na definição do esquema de operacionalização a ser utilizado.

As investigações que utilizam o referencial teórico do materialismo histórico e empregam o conceito de classe social em seu arsenal metodológico, operacionalizando-o enquanto ferramenta para a pesquisa empírica, podem cumprir dois propósitos diferentes (Elster, s.d.), contribuindo para identificar:

1) Por que os indivíduos diferem em termos de desvio, consumo, saúde ou hábitos;

2) que grupos organizados serão os atores principais na ação coletiva e no conflito social.

No primeiro objetivo, a investigação irá observar os diferenciais nas condições de vida, consumo, saúde entre as diversas classes sociais e frações de classe, buscando compreender estas diferenças a partir das relações de produção constituídas, das formas de inserção na produção, das relações de dominação-subordinação e da forma como o produto social é distribuído. Neste modelo a inserção de classe define um campo de probabilidades para o “padrão de consumo" de cada classe social e é identificada pela inserção produtiva de cada indivíduo/família participante do estudo.

No outro caso, a pretensão é identificar classes sociais, enquanto atores coletivos que agem no cenário político em determinada conjuntura. Aí, o que está em jogo não é a identificação de "padrões de consumo", e sim de "interesses coletivos" que são conflitantes entre as classes sociais e as potencialidades para a ação destes atores. Neste modelo, a inserção de classe define um conjunto de interesses, aspi rações de atores col etivos, e é definida em grande parte pela consciência de "fazer parte" de um "grupo de conflito".

Estes diferentes enfoques demandam critérios distintos de operacional ização, cada qual com um conjunto próprio de variáveis. Pode também derivar para o fato de o primeiro objetivo adotar um esquema de operacionalização para a análise empírica, enquanto o segundo "renega" tal opção metodológica, utilizando estratégias de investigação que não venham a requerer tal processo.

X. Variações conjunturais sobre os mediadores podem alterar as associações observadas entre a classe social e variáveis dependentes utilizadas na análise.

Maior ou menor intensidade da luta de classes em determinada conjuntura e possíveis modificações na distribuição de renda e nas formas políticas de exercício da dominação contribuem para variações observadas na análise empírica.

Wright (1981) traz como exemplo de fatores que determinam tais variações as formas específicas de segmentação do mercado de trabaIho ao interior da classe operária, as práticas legais que definem o poder dos gerentes sobre os trabalhadores. A análise da organização concreta das classes e suas condições de existência pode contribuir para identificar que papel estes mediadores estão exercendo e como influenciam as condições de existência das classes sociais.

No que diz respeito ao processo saúdedoença e ao acesso aos serviços de saúde, enquanto objetos de estudo, cabe registrar o papel de conjunturas recessivas, onde apresenta- 
se um aumento do desemprego e um "achatamento" salarial sobre as condições de vida das classes sociais que possuem condições de consumo precárias. Além disso, a forma de organização do Estado, as diretrizes das políticas sociais - principalmente da política de saúde são fundamentais na definição da oferta de serviços de saúde (quantidade, localização, tipo, população-alvo, prioridades, etc.), assim como de outros serviços públicos essenciais à qualidade de vida (saneamento, educação, transportes, lazer, etc.). Outro elemento importante refere-se à forma como o trabalho se encontra organizado e a incorporação de tecnologias produtivas, que podem estar relacionados ao aparecimento de determinados padrões de morbi-mortalidade entre as classes trabaIhadoras.

XI. A existência de duas ou mais inserções distintas na produção em um mesmo indivíduo cria outras dificuldades para a operacionalização do conceito de classe social.

A dupla inserção, fenômeno que ocorre em determinadas formações sócio-econômicas em proporções relevantes, apresenta outra questão a ser enfrentada pelo processo de operacionalização deste conceito. Esta situação em muito pode ser atribuída à realidade de instabilidade no emprego e de baixos salários, que demandam mais de uma inserção como forma de complementar a renda ou de representar uma alternativa de emprego no caso de demissão da outra atividade.

A opção geralmente utilizada é tentar identificar uma inserção como sendo a "principal", definida pelo próprio indivíduo, ou assumida pelo investigador com base em critérios como a maior estabilidade da inserção ou uma maior renda auferida através desta.

No primeiro critério - estabilidade -, uma inserção enquanto empregador ou pequeno proprietário dos meios de produção seria priorizada em relação a outra onde o indivíduo fosse assalariado. Da mesma forma, esta última seria principal se comparada a uma inserção enquanto autônomo sem qualificação.
O critério de renda pode ser criticável na medida em que uma inserção autônoma pode conjuntural mente contribuir mais para a renda do que uma assalariada, mas esta última teria a médio prazo, por sua maior estabilidade, maior importância para as condições de existência deste indivíduo.

Também nesta questão, as alternativas apresentam desdobramentos diversos, sendo que para cada uma delas podem ser levantadas críticas.

\section{Comentários finais}

Como foi possível observar, a maior parte dos limites aqui discutidos não são específicos do processo de operacionalização do conceito de classe social, dizendo respeito, principalmente, a questões de ordem metodológica, que constituem problemas enfrentados pelas investigações epidemiológicas que "invadem” o plano empírico com objetivo de compreender as determinações sociais relativas ao processo saúde-doença e ao acesso aos serviços de saúde.

No entanto, alguns problemas evidenciados são próprios da operacionalização deste conceito, sendo referentes a:

a) Necessi dade de adequá-lo, tanto à situação estrutural da sociedade estudada, quanto à variação de processos dinâmicos conjunturais; b) critérios adotados expressos através de variáveis quantitativas (renda e número de empregados);

c) resolução de questões teórico-conceituais fundamentais para a construção deste processo.

Tanto a primeira ordem de questões, quanto a segunda demandam um investimento no sentido de serem enfrentadas e superadas. Estes "obstáculos metodológicos" precisam ser transpostos.

Esperamos que a Epidemiologia continue a desenvolver estudos que avancem este tipo de linha investigativa, assumindo os desafios que aqui tentamos especificar e conseguindo superá-los.

\section{Agradecimentos}

Ao Prof. Eduardo Mota (orientador de nossa dissertação de mestrado) e às colegas Rosana Aquino, Maria Guadalupe Medina e Letícia Nobre, que deram importantes contribuições à versão final deste artigo. 


\section{Referências}

ALMEIDA FILHO, N. de, 1989. Epidemiologia sem Números: Uma Introdução Crítica à Ciência Epidemiológica. Rio de Janeiro: Campus.

ALMEIDA FILHO, N. de, 1992. A Clínica ea Epidemiologia. Salvador: APCE/Rio de Janeiro: ABRASCO.

BARRETO, M. L., 1990. A epidemiologia, sua história e crises: notas para pensar o futuro. In: Epidemiologia. Teoria e Objeto (D. C. Costa, org.), pp. 19-38, São Paulo: HUCITEC-ABRASCO.

BARROS, F. C. \& VICTORA, C. G., 1991. Epidemiologia da Saúde Infantil: Um Manual para Diagnósticos Comunitários. São Paulo: HUCITEC-UNICEF.

BARROS, M. B. de A., 1986. A utilização do conceito de classe social nos estudos dos perfis epidemiológicos: uma proposta. Revista de Saúde Pública, 20:269-273.

BREILH, J., 1989. La Reprodución Social y el Proceso Epidemiológico. (mimeo.)

BREILH, J. \& GRANDA, E., 1986. Investi gação de Saúde na Sociedade: Guia Pedagógico sobre um Novo Enfoque do Método Epidemiológico. São Paulo: Instituto de Saúde/ Rio de Janeiro: ABRASCO.

BRONFMAN, M. \&TUIRÁN, R., 1984. La desigualdad ante la muerte: clases sociales y mortalidad en la niñez. Cuadernos Médico-Sociales, 29/30:53-75.

BRONFMAN, M., VICTORA, C., LOMBARDI, C.; BARROS F. C.; BERIA, J. U. \& TEIXEIRA, A. M. B., 1988. Operacionalização do conceito de classe social em estudos epidemiológicos. Revista de Saúde Pública, 22:253-265.

CEAS (Centros de Estudios y Asesoría en Salud), 1990. Desarrollo de la Medicina Social en América Latina. Componente de Metodología. Quito: CEAS (mimeo.)

ELSTER, J., s.d. Marx Hoje. Rio de Janeiro: Paz eTerra.

JIMÉNEZ, A. T., 1982. Formación económico-social y enfermedad. In: Enfermedad y Clase Obrera (A. T. Jiménez ,org.), pp. 11-40, México: Instituto Politécnico, Escuela de Enfermeria y Obstetricia.
KLEINBAUM, D. G.; KUPPER, L. L. \& MORGENSTERN, H., 1982. Epidemi ologic Research. Principles and Quantitative Methods. New York: Lifetime Learning Publications.

LENIN, V. I., 1980. Uma grande iniciativa. In: Obras Escolhidas, Vol. 3 (V. I. Lenin) pp. 139-60, São Paulo: Editora Alfa-Omega.

POULANTZAS, N., 1977. As classes sociais. In: As Classes Sociais na América Latina: Problemas de Conceituação (R. B. Zenteno, org.), pp. 91-116, Rio de Janeiro: Paz eTerra.

PRZEWORSKY, A., 1989. Capitalismo e Social-Democracia. São Paulo: Companhia das Letras.

SOLLA, J. J. S. P., 1990. Algumas considerações sobre a utilização do conceito de "classe social" na investigação epidemiológica. Saúde em Debate, 30:26-31.

SOLLA, J. J. S. P., 1992. Classe Social eSaúde: Um Estudo sobre a Utilização deste Concei to na Investigação Epidemiológica. Dissertação de Mestrado, Salvador: Faculdade de Medicina, Universidade Federal da Bahia.

UFBA/FAMED/DMP (Universidade Federal da Bahia/ Faculdade de Medicina/ Departamento de Medicina Preventiva), 1986. Projeto: A Morbi-Mortalidade Materno-infantil em Salvador, Bahia: Características Epidemiológicas, Fatores de Risco e Determinantes Sócio-Econômicos, Salvador. (mimeo.)

VICTORA, C. G.; FACCHINI, L. A.; BARROS, F. C. \& LOMBARDI, C., 1990. Pobreza e Saúde: como medir nível sócio-econômico em estudos epidemiológicos de saúde infantil. Anais do 1o Congresso Brasileiro de Epidemiologia, pp. 302-315, Campinas: Abrasco.

WRIGHT, E. O., 1981. Classe, Crise e Estado. Rio de Janeiro: Zahar.

WRIGHT, E. O., 1985. Classes. London: Verso. 